\title{
DESIGN OF CIRCULAR COMPOSITE BEAMS WITH A DIFFERENT CONCRETE CORE CONSIDERING THE EFFECT OF CONCRETE IN TENSION
}

\author{
Audronis Kazimieras KVEDARAS ${ }^{\mathrm{a}}$, Gintas ŠAUČIUVĖNAS ${ }^{\mathrm{b}}$, Arūnas KOMKA ${ }^{\mathrm{b}}$, \\ Algirdas JUOZAPAITIS ${ }^{c}$ \\ ${ }^{a}$ Research Laboratory of Building Composite Structures "Kompozitas", \\ Vilnius Gediminas Technical University, Sauletekio al. 11, LT-10223 Vilnius, Lithuania \\ ${ }^{b}$ Department of Steel and Timber Structures, Vilnius Gediminas Technical University, \\ Sauletekio al. 11, LT-10223 Vilnius, Lithuania \\ ${ }^{c}$ Department of Bridges and Special Structures, Vilnius Gediminas Technical University, \\ Sauletekio al. 11, LT-10223 Vilnius, Lithuania
}

Received 11 May 2015; accepted 21 Sep 2015

\begin{abstract}
Currently, the bending resistance of composite steel and concrete circular beams and beam-columns may be analysed assuming the interaction between the steel shell and concrete core but ignoring the behaviour of the part of the concrete core in tension. Some natural and numerical experiments show that an influence of this part of the concrete core on the total value of bending resistance of a composite member may be rather important. Therefore, this paper presents the method developed for the design of hollow and solid concrete-filled steel tubular beams based on the test data. It takes into account an effect of the part of the concrete core in tension and gives a better agreement with test results than EC4 (EN 1994-1-1 2004). Also, the paper presents the results of carried out analytical, experimental and numerical investigations of the hollow centrifuged and solid concrete-filled steel tubular beams.
\end{abstract}

Keywords: concrete-filled steel tubes, beams, effect of tension, stress distribution, resistance.

\section{Introduction}

The overall interaction between the external thin-walled steel tube and the internal concrete core significantly increases the resistance of stub concrete-filled circular steel tubular members under axial compression. This circumstance may be important using slender composite steel and concrete members, for which the recommendation is given in the paragraph 6.7.2(4) of EN 1994-1-1 (2004) stating that full composite action up to failure may be assumed between the steel and concrete components of the member, because the increase in strength of concrete and, perhaps, of steel caused by confinement should exist under different loading conditions - uniaxial and eccentric compression and tension, bending, etc. The higher efficiency of slender differently loaded members, especially if they are hollow, against the short ones was obtained in some natural experiments. However, this contradicts the limitation of EN 1994-1-1 (2004). Besides, account may be taken of the increase in the strength of concrete caused by confinement if the relative slenderness does not exceed 0.5 and $e / d<0.1$ (where $e$ is the eccentricity of load applied to a cross-section, and $d$ is an external diameter of this cross-section). Therefore, further investigations into the behaviour of slender composite steel and concrete members, especially flexural ones, are necessary to develop the more effective design methods.

To widen the scope of application of composite steel and concrete structures, the possibility was presented to develop members with a hollow concrete core that could be used effectively as beams and girders (Matzumoto et al. 1976). One of the main advantages of circular composite steel and concrete structures (Elchalakani et al. 2001; Kuranovas, Kvedaras 2007) is the interaction between the external steel tube and the internal concrete core: concrete delays the local buckling of the steel tube, whereas the steel tube confines and strengthens concrete. A recent investigation by Jiang et al. (2013) of composite beams considered the design of thin-walled centrifugal concrete-filled steel tubes, for which an accurate finite element model was developed and verified based on the experimental results, but since it is difficult to calculate the design bending resistance according to the FEA model and the exact parametric method, the empirical equations were proposed for simplicity to predict the bending resistance with reasonable accuracy. Some other researches carried out in the field of various composite steel and concrete beams and other flexural members should be mentioned as well (e.g. Han 2004; Douglas

Corresponding author: Gintas Šaučiuvènas

E-mail: gintas.sauciuvenas@vgtu.lt 
Good et al. 2010; Wheeler, Bridge 2011; Bahrami et al. 2013). The flexural behaviour of steel-concrete composite cross-sections as sections for beams was experimentally investigated and analysed by Soundararajan and Shanmugasundaram (2008), Uenaka and Kitoh (2011) and Valsa Ipe et al. (2013).

Currently, the bending resistance of composite steel and concrete circular beams and beam-columns may be analysed assuming the interaction between the steel shell and the concrete core but ignoring the behaviour of the part of the concrete core in tension. Some natural and numerical experiments showed that an influence of this part of the concrete core on the total value of bending resistance of the composite member may be somewhat important. Therefore, the developed method for the design of hollow and solid concrete-filled steel tubular beams based on test data, which may also consider the effect of the part of the concrete core in tension, is presented. The results of our analytical, experimental and numerical investigations of concrete-filled steel tubular beams with the solid and hollow centrifuged concrete cores are presented in this paper. Results of the bending resistance of circular concrete-filled steel tubular beams with hollow and solid concrete cores obtained considering the effect of the concrete in tension sometimes differ insignificantly from the results of analytical calculations when this effect is ignored.

\section{General concept used in the design of beams}

\subsection{Usual behaviour modelling of circular concrete- filled steel tubular beams}

The uniaxial bending moment of resistance for a circular composite concrete-filled steel tubular beam is usually calculated using the ideally plastic material models for concrete and steel (see Fig. 1). The elastic-plastic behaviour of the composite concrete-filled steel tubular beam is fixed during natural and numerical tests. Similar models may also be made for members with other forms of concrete cores.

\subsection{The effect of concrete core in tension}

In the model (Fig. 2), the plastic neutral axis is fixed by central angles $\theta$ visible in diagrams of distribution of steel and concrete stresses, which are taken as ideally plastic and corresponding to the rectangular diagrams. This model takes into account not only compression $N_{c c}$, but also tension $N_{c t}$ internal forces resisted by the concrete core. Forces $N_{c c}$ and $2 N_{a 2}$ are ignored because the bending moments of both tension forces $\left(N_{a 1}\right.$ and $\left.N_{c t}\right)$ are written about their common centre $\left(e_{u}\right)$.

The design plastic moment of resistance $M_{p l, R d}$ is defined by the plastic axial compression resistance $N_{p l, R d}$ of the steel cross-section and the design eccentricity $e_{u}$,

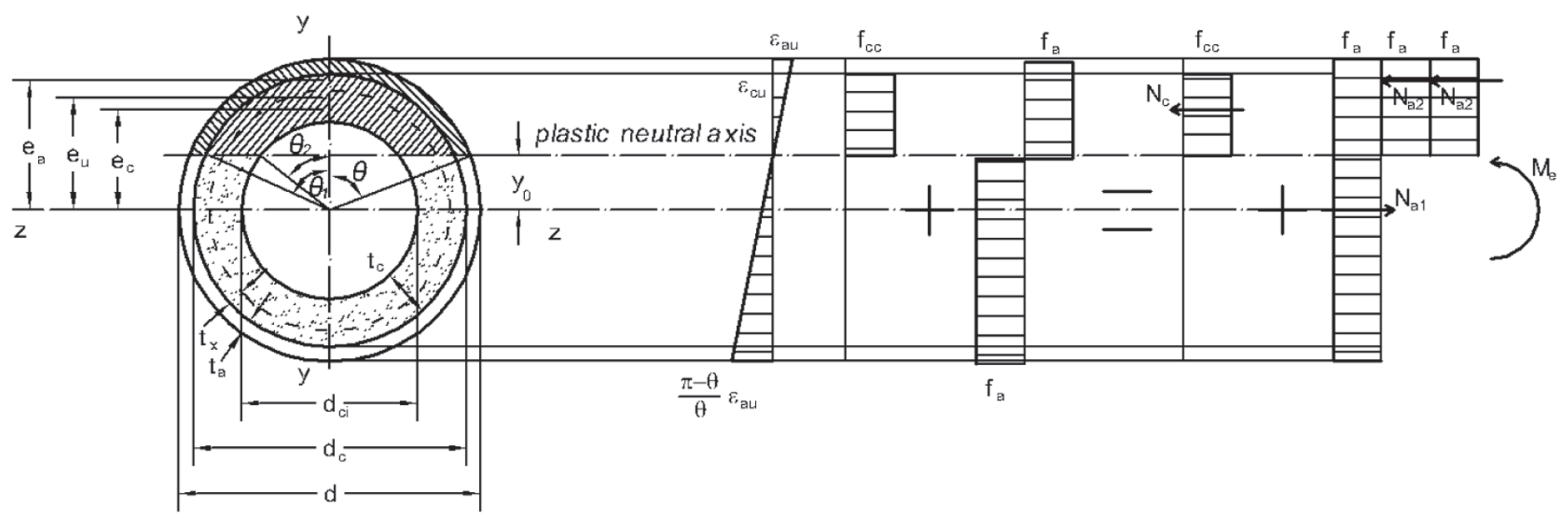

Fig. 1. Diagrams of linear strain and ideally plastic stress distributions in the hollow concrete-filled steel tubular cross-section

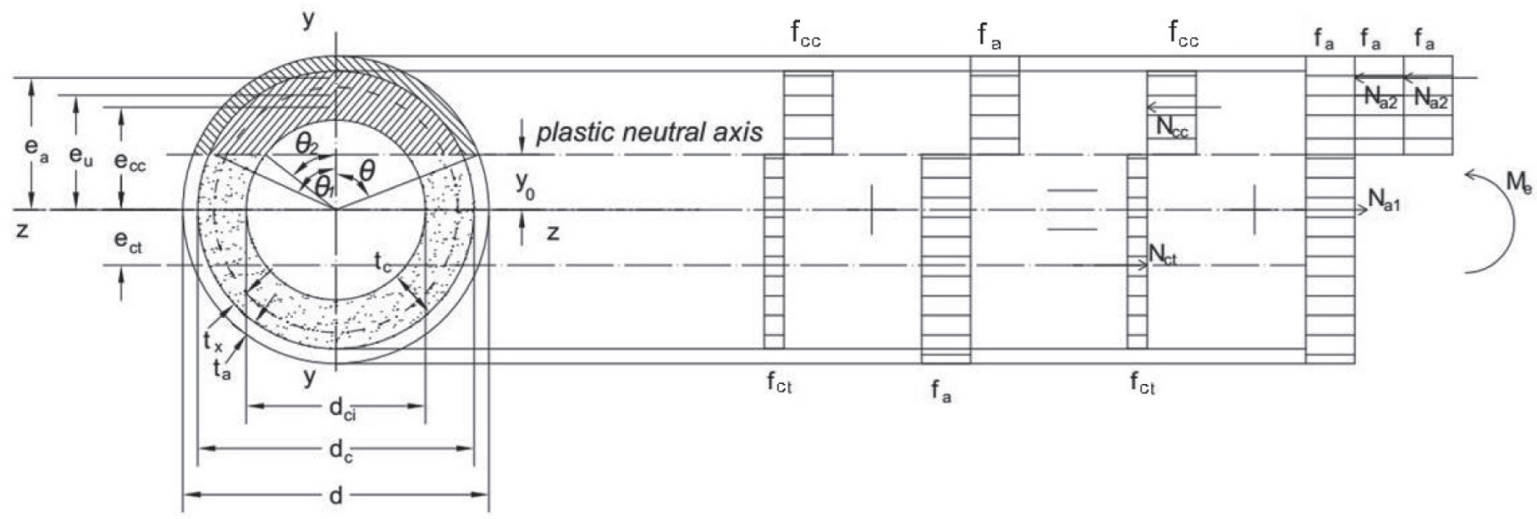

Fig. 2. Stress distribution in the steel and concrete circular cross-sections experiencing bending, taking into account tension of the concrete core 
which depends on the type of member cross-section adding the moment from the tension force $N_{c t}$ of concrete core:

$$
\begin{gathered}
N_{p l, R d}=A_{a} \cdot f_{u d} ; \quad N_{c t, R d}=A_{c t} \cdot f_{c t, d} ; \\
M_{p l, R d}=N_{p l, R d} \cdot e_{u}+N_{c t, R d} \cdot\left(e_{u}+e_{c t}\right) .
\end{gathered}
$$

Methods presented by Kvedaras et al. (2013) were used for definition of bending resistance of the circular composite concrete-filled steel tubular beams, estimating the strength of steel and concrete in such members under multi-axial stress states and based on the criteria of small elastic-plastic strains and on the law of generalised curves from the theory of plasticity.

The value of the design ultimate tensile strength $f_{u}$ applied in Eqn (1) for different types and dimensions of members may vary; therefore, it is marked further as $f_{a}$ :

$$
\begin{aligned}
& \text { If } k_{a} \cdot k_{w}<f_{y} \text {, then } f_{a}=f_{y} ; f_{c t}=0.1 f_{c c} ; \\
& \text { If } f_{y} \leq k_{a} \cdot k_{w}<f_{u} \text {, then } f_{a}=\eta_{a} \cdot f_{y} ; f_{c t}=0.1 f_{c c} ; \\
& \text { If } \quad k_{a} \cdot k_{w} \geq f_{u} \text {, then } f_{a}=\eta_{a} \cdot f_{u} ; f_{c t}=0.1 f_{c c},
\end{aligned}
$$

where:

$$
\begin{gathered}
k_{a}=E_{c} \cdot A_{c c} / E_{a} \cdot A_{a} \geq 1 ; \\
k_{w}=f_{y} \cdot W_{p} / W
\end{gathered}
$$

where: $W_{p}$ and $W$ - plastic and elastic section modulus of steel shells, respectively; $\eta_{a}=1.074$ is the constraining factor as a random variable value characterising the interaction effect of the components of a composite concrete-filled member on its resistance under compression or tension (Kvedaras, Kudzys 2010); $f_{y}$ and $f_{u}$ are the nominal values of steel yield and ultimate tensile strengths.

\subsection{Real behaviour modelling of circular concrete- filled tubular beams}

One of the most important parameters characterising the bending resistance of composite steel and concrete members is the distance of plastic neutral axis from the main sectional axis. Knowing the position of the plastic neutral axis, which divides parts of the compression and tension of the composite cross-section and the material characteristics of the composite member, the possibility to define the exact bending resistance of such member exist. Kvedaras (1999) suggested expressions for angle $\theta$ defining the position of the plastic neutral axis for circular composite beams with a solid and hollow concrete core:

$$
\theta=\cos \left\{\begin{array}{l}
{\left[1-\frac{2\left(t+t_{x}\right)}{d}\right]^{k} \times} \\
\cos \left[\frac{A_{c}}{t_{x}\left(d-2 t-t_{x}\right)+2 t\left(d-t_{x}\right)}\right]
\end{array}\right\}^{-1} .
$$

Eqn (8) is derived to modify the composite sections into the hollow circular steel sections, in which the core thickness $t_{x}$ represents the thickness of a relative steel hollow core by strength corresponding to the a solid or hollow concrete core. Using the values of the angle $\theta$ that were determined according to Eqn (8) it's possible to calculate the ultimate values of bending resistance for circular composite beams with solid and hollow concrete cores. However, these values of the angle $\theta$ cannot be used to determine the exact value of the distance between the plastic neutral axis and the main sectional axis $z-z$ of this composite section. Therefore, the next expression was applied for the definition of the angle $\theta_{t}$ of the composite section with account of the part of concrete core in tension proposed by Kvedaras and Kudzys (2010):

$\theta_{t}=\pi \cdot f_{y} \cdot A_{a} /\left[2 \cdot f_{y} \cdot A_{a}+0.5 \cdot\left(1+r_{c} / r_{a}\right) \cdot f_{c} \cdot A_{c}\right]$,

where: $r_{c}=d_{c} / 2$ and $r_{a}=d / 2$ (Figs 1 and 2).

The distance of the plastic neutral axis from the main axis $z-z$ of the hollow circular section $y_{0}$ is expressed as:

$$
y_{0}=0.5 \cdot d \cdot \sin \left(\left(0.5 \cdot \pi-\theta_{t}\right) \cdot 180 / \pi\right) \text {. }
$$

\section{Natural and numerical experiments with composite beams}

Composite steel and concrete elements were tested using 4-point bending. The samples were tested until the loss of load bearing capacity. During the tests, stresses in the middle section of the beam and the vertical displacement were recorded. The obtained test results were compared with the results obtained by numerical simulation and analytical calculation.

Numerical simulation of bending composite elements was done using software COMSOL (2010). Interaction of the concrete core and the steel shell was modelled using the full composite action meaning that $2 \mathrm{D}$ and/or $3 \mathrm{D}$ stress state arises in the steel and concrete components of differently loaded members, e.g., using the Ottosen's parameters (CEB-FIB 1993); and for nonlinear analysis, using the Murnaghan's and Lame's parameters (Montoya et al. 2006; Pereira, Barros 2009). Three main parameters were compared: load bearing capacity, beam deflection and the neutral axis position.

Figure 3 presents the position of the plastic neutral axis in circular composite beams with a solid concrete core (steel tube $\varnothing 108 \times 2.25 \mathrm{~mm}$ ) and in circular composite beams with a hollow centrifuged concrete core (steel tube $\varnothing 219 \times 1.6 \mathrm{~mm}$ ) received from the above mentioned numerical simulation. 


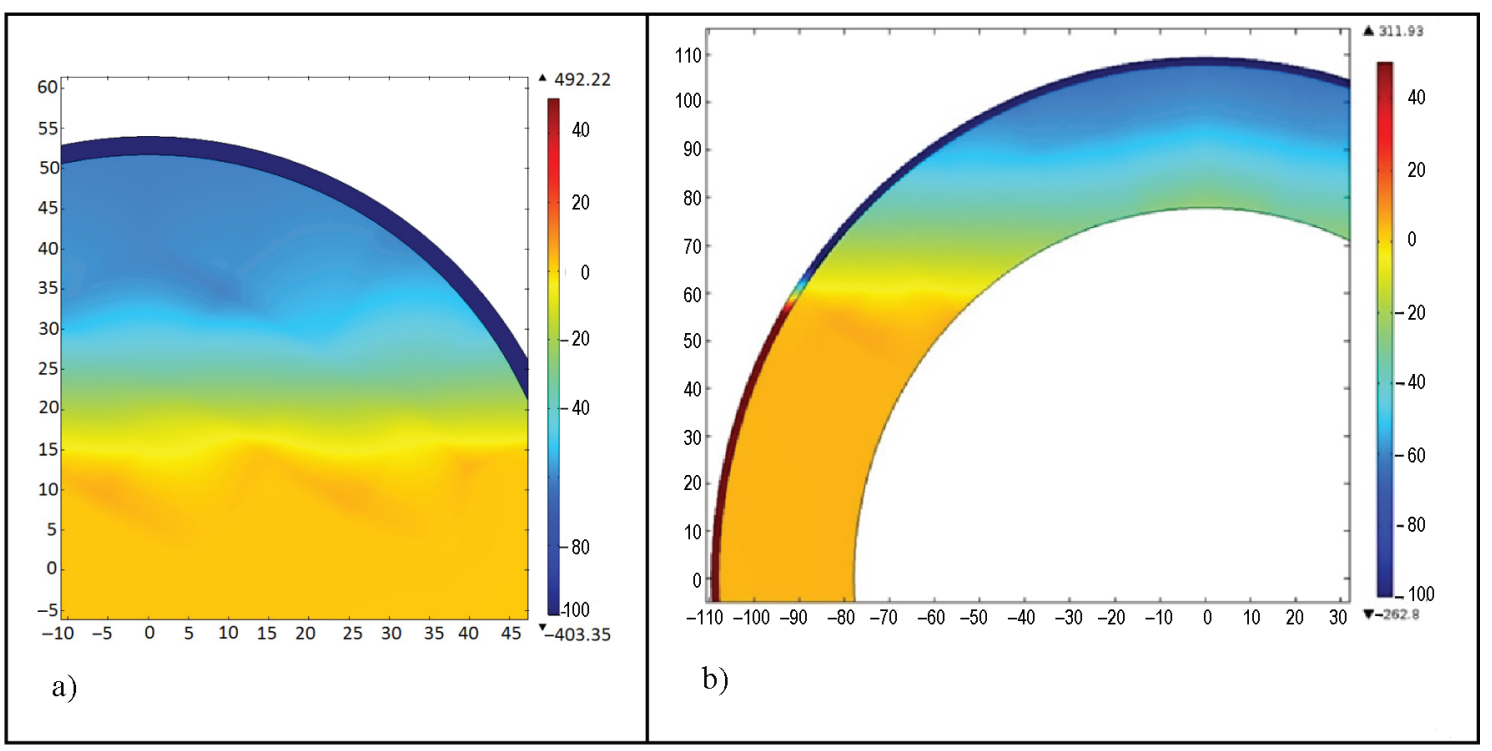

Fig. 3. a) Position of the plastic neutral axis in circular composite beams with a solid concrete core $(\varnothing 108 \times 2.25)$; b) in circular composite beams with a hollow concrete core $(\varnothing 219 \times 1.6)$

The material properties of tested, analytically calculated and numerically simulated circular composite beams with solid and hollow concrete cores are presented in Table 1.

Bending elements made from steel tubes with an external diameter of $108 \mathrm{~mm}$ and thickness of $2.25 \mathrm{~mm}$ were fully filled with concrete. The length of beams was $2.0 \mathrm{~m}$, the distance between supports was $1.8 \mathrm{~m}$ and the distance between the load adding points $-0.6 \mathrm{~m}$. The calculations of load bearing capacity and numerical simulation were carried out using the actual strength values of tube steel and in-fill core concrete. Mean values of steel strength were as follow: yield strength $-400 \mathrm{MPa}$ and the ultimate tensile strength $-471 \mathrm{MPa}$. The class of concrete core according to EN 206-1 (2014) was C20/25.

Other beams were made from steel tubes with an external diameter of $219 \mathrm{~mm}$, thicknesses of $1.60 \mathrm{~mm}$ and $4.50 \mathrm{~mm}$, and were filled with the hollow concrete core formed by centrifuging. The length of beams was
$3.40 \mathrm{~m}$ and $3.60 \mathrm{~m}$, the distance between the supports was $3.0 \mathrm{~m}$ and the distance between the load adding points was $1.0 \mathrm{~m}$.

The mean values of steel strength were as follow: yield strength - $250 \mathrm{MPa}$ and about $283 \mathrm{MPa}$, and the ultimate tensile strength - $374 \mathrm{MPa}$ and about $350 \mathrm{MPa}$, respectively. The nominal cylindrical strength of concrete was $30.0 \mathrm{MPa}$ and about $28.0 \mathrm{MPa}$, respectively.

\section{Comparison of analysed results}

Table 2 provides the experimental values of the ultimate bending moment $M_{u, e x p}$, the analytical $M_{u, t}$ and the analytical bending moment $M_{u, t, t}$, considering the contribution of concrete strength in the tension zone to investigated concrete-filled steel CHS beams.

It was found that super thin-walled steel shell may be used when bending a composite simple beam until the ultimate steel strength is reached at failure. Therefore, such simple hollow concrete-filled circular steel tubular

Table 1. Material properties of tested and analysed circular composite beams

\begin{tabular}{|c|c|c|c|c|}
\hline \multirow{2}{*}{$\begin{array}{l}\text { Specimen } \\
\text { No. }\end{array}$} & \multirow{2}{*}{ Dimensions of tube $d \times t_{a}(\mathrm{~mm})$} & \multicolumn{2}{|c|}{ Steel strength $(\mathrm{MPa})$} & \multirow{2}{*}{$\begin{array}{c}\text { Concrete strength } f_{\mathrm{c}} \\
(\mathrm{MPa})\end{array}$} \\
\hline & & $f_{y}$ & $f_{u}$ & \\
\hline \multicolumn{5}{|c|}{ Steel tube $\varnothing 108 \times 2.25 \mathrm{~mm}$, solid concrete core } \\
\hline 1. & $108 \times 2.25$ & 400.6 & 471.1 & 30.1 \\
\hline 2. & $108 \times 2.25$ & 400.6 & 471.1 & 28.7 \\
\hline 3. & $108 \times 2.25$ & 400.6 & 471.1 & 30.1 \\
\hline \multicolumn{5}{|c|}{ Steel tube $\varnothing 219 \times 1.6 \mathrm{~mm}$, hollow concrete core of $30 \mathrm{~mm}$ in thickness } \\
\hline 1. & $219 \times 1.6$ & 250.0 & 374.2 & 23.7 \\
\hline 2. & $219 \times 1.6$ & 250.0 & 374.2 & 23.7 \\
\hline 3. & $219 \times 1.6$ & 250.0 & 374.2 & 25.9 \\
\hline \multicolumn{5}{|c|}{ Steel tube $\varnothing 219 \times 4.5 \mathrm{~mm}$, hollow concrete core of $30 \mathrm{~mm}$ in thickness } \\
\hline 1. & $219 \times 4.5$ & 296.0 & 349.3 & 31.9 \\
\hline 2. & $219 \times 4.5$ & 273.2 & 347.1 & 32.0 \\
\hline 3. & $219 \times 4.5$ & 283.5 & 353.0 & 39.9 \\
\hline
\end{tabular}


Table 2. Comparison of the results of experimental and theoretical load bearing capacities

\begin{tabular}{|c|c|c|c|c|c|}
\hline \multirow[b]{2}{*}{ Specimen No. } & \multicolumn{3}{|c|}{ Values of ultimate bending moments $(\mathrm{kN} \mathrm{m})$} & \multicolumn{2}{|c|}{ Relationships } \\
\hline & Experimental, $M_{u, \exp }$ & $\begin{array}{c}\text { Analytical } M_{u, t} \\
\text { (Kvedaras } 1999 \text { ) }\end{array}$ & $\begin{array}{c}\text { Analytical } \\
M_{u, t, t}\end{array}$ & $M_{u, \exp } / M_{u, t}$ & $M_{u, \exp } / M_{u, t, t}$ \\
\hline \multicolumn{6}{|c|}{ Steel tube $\varnothing 108 \times 2.25 \mathrm{~mm}$, solid concrete core } \\
\hline 1. & 14.4 & 12.85 & 11.57 & 1.121 & 1.245 \\
\hline 2. & 14.4 & 12.82 & 11.57 & 1.123 & 1.245 \\
\hline 3. & 12.9 & 12.85 & 11.65 & 1.004 & 1.107 \\
\hline Mean value & 13.9 & 12.84 & 11.60 & 1.083 & 1.199 \\
\hline \multicolumn{6}{|c|}{ Steel tube $\varnothing 219 \times 1.6 \mathrm{~mm}$, hollow concrete core of $30 \mathrm{~mm}$ in thickness } \\
\hline 1. & 27.0 & 26.65 & 26.70 & 1.015 & 1.011 \\
\hline 2. & 27.0 & 26.65 & 26.70 & 1.015 & 1.011 \\
\hline 3. & 33.1 & 26,77 & 27.21 & 1.236 & 1.216 \\
\hline Mean value & 29.03 & 26,69 & 26.87 & 1.089 & 1.080 \\
\hline \multicolumn{6}{|c|}{ Steel tube $\varnothing 219 \times 4.5 \mathrm{~mm}$, hollow concrete core of $30 \mathrm{~mm}$ in thickness } \\
\hline 1. & - & 66.28 & 67.17 & - & \\
\hline 2. & 59.9 & 61.50 & 62.50 & 0.974 & 0.958 \\
\hline 3. & 62.7 & 64,43 & 66.21 & 0.973 & 0.947 \\
\hline Mean value & 61.3 & 64.07 & 65.29 & 0.974 & 0.953 \\
\hline
\end{tabular}

Table 3. Comparison of the distance $y_{0}$ of neutral plastic axis

\begin{tabular}{c|c|c|c|c}
\hline \multirow{2}{*}{ Element } & \multicolumn{2}{|c|}{ Distance of plastic neutral axis $y_{0}[\mathrm{~mm}]$ due to: } & Relationship \\
\cline { 2 - 5 } & Kvedaras (1999) & $\begin{array}{c}\text { Elchalakani } \text { et al. } \\
(2001)\end{array}$ & $\begin{array}{c}\text { Numerical } \\
\text { simulation }\end{array}$ & $\begin{array}{c}\text { Kvedaras }(1999) / \\
\text { Numerical }\end{array}$ \\
\hline$\varnothing 108 \times 2.25$ (solid core) & 17.95 & 21.41 & 16.00 & 1.12 \\
\hline$\varnothing 219 \times 1.6$ (hollow core) & 68.45 & - & 62.00 & 1.10 \\
\hline$\varnothing 219 \times 4.5$ (hollow core) & 41.94 & - & 38.00 & 1.10 \\
\hline
\end{tabular}

beams may be more effective than short columns of the similar composite cross-section. Therefore, simple beams made of super thin-walled CHS with a hollow centrifuged concrete core may be more competitive than flexural members made of steel and reinforced concrete and even against more effective their geometrical forms than CHS.

The failure of CHS elements with a concrete core is not sudden. Therefore, they can be used safely. In addition, according to the methods based on main principals and presumptions of the theory of plasticity of small elastic-plastic strains, the possibility exists of a rather exact theoretical definition of the ultimate load of composite elements and of avoidance of their overloading during service time.

The partial results received by a numerical simulation may be illustrated using the following data:

- For a composite beam with a steel tube of $\varnothing 108 \times 2.25 \mathrm{~mm}$ and a solid concrete core when the experimental mean value of the ultimate bending moment is $13.9 \mathrm{kNm}$, the value of the same moment received by numerical simulation is $13.77 \mathrm{kNm}$;

- For a composite beam with a steel tube of $\varnothing 219 \times 1.60 \mathrm{~mm}$ and a hollow centrifuged concrete core of $30.0 \mathrm{~mm}$ in thickness, when the experimental mean value of the ultimate bending moment is $29.03 \mathrm{kNm}$, the value of the same moment received by numerical simulation is $31.25 \mathrm{kNm}$;

- For a composite beam with a steel tube of $\varnothing 108 \times 2.25 \mathrm{~mm}$ and a solid concrete core when the experimental value of the ultimate deflection is
$44.5 \mathrm{~mm}$, the value of the same deflection received by numerical simulation is $42.5 \mathrm{~mm}$.

Table 3 presents the comparison of the results of analytical calculation and numerical simulation of the distance $y_{0}$ of the neutral plastic axis from the main sectional axis $z-z$ of circular composite beams with hollow and solid concrete cores.

The investigation shows that results obtained from the numerical simulation are less safe in comparison with the results obtained by test and analytical calculation because ultimate values of action effects received by numerical simulation are greater than those of deflections and the distance of neutral plastic axis.

\section{Conclusions}

1. The experimental and analytical data on hollow and solid concrete-filled circular steel tubular simple beams showed their structural and constructional efficiency.

2. A rather high effect of an interaction between steel tubes and concrete cores on their constraining factors and the ultimate strength of flexural composite members were established.

3 . The proposed analytical method has a good agreement with the natural and numerical test results with hollow centrifuged and solid concrete-filled circular steel tubular simple beams, which allows recommending the presented method for the use in the design practice of such efficient composite beams. 
4. Results of the bending resistance of circular concrete filled steel tubular beams with hollow and solid concrete cores, obtained considering the effect of concrete in tension, do not differ much from the results when this effect is ignored.

\section{References}

Bahrami, A.; Wan Badaruzzaman, W. H.; Osman, S. A. 2013. Investigation of concrete-filled steel composite (CFSC) stub columns with bar stiffeners, Journal of Civil Engineering and Management 19(3): 433-446. http://dx.doi.org/10.3846/13923730.2013.768545

CEB-FIB. 1993. CEB-FIB Model Code 1990 - Design Code. Thomas Telford. $460 \mathrm{p}$.

COMSOL. 2010. Multiphysics user's guide. COMSOL, AB.

Douglas Goode, C.; Kuranovas, A.; Kvedaras, A. K. 2010. Buckling of slender composite concrete-filled steel columns, Journal of Civil Engineering and Management 16(2): 230-237. http://dx.doi.org/10.3846/jcem.2010.26

EN 1994-1-1 Design of composite steel and concrete structures - Part 1-1: General rules and rules for buildings. Brussels: CEN, 2004.

EN 206-1 Concrete - Part 1: Specification, performance, production and conformity. Brussels: CEN, 2014.

Elchalakani, M.; Zhao, X. L.; Grzebieta, R. H. 2001. Concretefilled circular steel tubes subjected to pure bending, Journal of Constructional Steel Research 57(11): 1141-1168. http://dx.doi.org/10.1016/S0143-974X(01)00035-9

Han, L. H. 2004. Flexural behaviour of concrete filled steel tubes, Journal of Constructional Steel Research 60(2): 313-337. http://dx.doi.org/10.1016/j.jcsr.2003.08.009

Jiang, A.-Y.; Chen, J.; Jin, W.-L. 2013. Bending strength of thin walled centrifugal concrete-filled steel tubes, Research Journal of Applied Sciences, Engineering and Technology 5(3): 801-811.

Kuranovas, A.; Kvedaras, A. K. 2007. Behaviour of hollow concrete-filled steel tubular composite elements, Journal of Civil Engineering and Management 13(2): 131-141.

Kvedaras, A. K. 1999. Light-weight hollow concrete-filled steel tubular members in bending, Light-Weight Steel and Aluminium Structures, Fourth International Conference on
Steel and Aluminium Structures (ICSAS'99), 20-23 June 1999, Espoo, Finland, 755-760.

Kvedaras, A. K.; Kudzys, A. 2010. Tubular composite beamcolumns of annular cross-sections and their design practice, Steel and Composite Structures 10(2): 109-128. http://dx.doi.org/10.12989/scs.2010.10.2.109

Kvedaras, A. K.; Šaučiuvènas, G.; Jarmolajeva, E. 2013, Behaviour of hollow and solid concrete-filled circular steel tubular simple beams, in Proc. of International Conference "Design, Fabrication and Economy of Metal Structures", 24-26 April 2013, Miskolc, Hungary, 569-576.

Matzumoto, Y.; Fukuzawa, K.; Endo, H. 1976. Manufacture and behaviour of hollow composite members, Final Report of $10^{\text {th }}$ Congress of IABSE, 6-11 September 1976, Tokyo, Japan, 389-394.

Montoya, E.; Vecchio, F. J.; Shleikh, S. A. 2006. Compression field modeling of confined concrete: constitutive models, Jornal of Materials in Civil Engineering 18(4): 510-517.

http://dx.doi.org/10.1061/(ASCE)0899-1561(2006)18:4(510)

Pereira, E. B.; Barros, J. A. O. 2009. 3D behaviour of a 4 parameter isotropic nonlinear hardening plasticity model for concrete, in CMNE 2009 - Congress on Numerical Methods in Engineering, 29 June - 2 July 2009, SEMNI, Barcelona, Spain, 1-20.

Soundararajan, A.; Shanmugasundaram, K. 2008, Flexural behaviour of concrete-filled steel hollow sections beams, Journal of Civil Engineering and Management 14(2): 107-114. http://dx.doi.org/10.3846/1392-3730.2008.14.5

Uenaka, K.; Kitoh, H. 2011 Mechanical behavior of concrete filled double skin tubular circular deep beams, ThinWalled Structures 49(2): 256-263. http://dx.doi.org/10.1016/j.tws.2010.10.005

Valsa Ipe, T.; Sharada Bai, H.; Manjula Vani, K.; Iqbal, M. 2013. Flexural behavior of cold-formed steel concrete composite beams, Steel and Composite Structures 14(2): 105-120. http://dx.doi.org/10.12989/scs.2013.14.2.105

Wheeler, A.; Bridge, R. 2011. Flexural behaviour of concretefilled thin-walled steel tubes with longitudinal reinforcement, in Proc. of the Sixth International Conference on Composite Construction in Steel and Concrete, 20-24 July 2008, Devil's Thumb Ranch in Tabernash, Colorado, USA, 225-236.

Audronis Kazimieras KVEDARAS. Doctor Habil. (Dr Sc), former Professor of Department of Steel and Timber Structures of Vilnius Gediminas Technical University. Research interest: Behaviour of steel, composite steel-concrete, composite timber-concrete and structural glass structures, methods of calculation and codes. He is a member of IABSE and ASCCS, and invited NATO expert $(1996,2000)$.

Gintas ŠAUČIUVĖNAS. Assoc. Prof. Dr, Department of Steel and Timber Structures, Vilnius Gediminas Technical University. Research interests: Evaluation of existing steel and timber structures, evaluation of fire resistance of steel and timber structures, behaviour analysis of the elements and structures made of steel, timber, glass and steel-concrete composite.

Arūnas KOMKA. Assoc. Prof. Dr, Department of Steel and Timber Structures, Vilnius Gediminas Technical University. Research interests: analysis and design of steel, timber and composite structures.

Algirdas JUOZAPAITIS. Dr Professor, Department of Bridges and Special Structures, Vilnius Gediminas Technical University, Research interests: Innovative Structural Systems of Steel Bridges and Special Structures, Geometrically Nonlinear Analysis and Stability of Steel Structures, Control of Internal Forces in Steel Bridges and Special Structures. 